\title{
BERTRAND RUSSELL E A CURA DOS PROVINCIALISMOS POR MEIO DO ENSINO DA HISTÓRIA
}

\author{
BERTRAND RUSSELL AND THE HEALING OF PROVINCIALISMS THROUGH \\ HISTORY TEACHING
}

Júlio César Augusto do Valle ${ }^{1}$

\begin{abstract}
RESUMO: O propósito deste artigo consiste em oferecer ao historiador e também ao professor de história elementos que orientaram a perspectiva de Bertrand Russell, matemático e filósofo reconhecido no século $X X$, sobre estas áreas de estudos. Assim, no cerne do debate está a "cura dos provincialismos" - expressão muito utilizada por Russell - que o ensino da história pode proporcionar aos educandos. Para isto, há também a elucidação de um possível diálogo entre Russell e Freire no que tange aos receios freireanos com o fatalismo que corrompe o senso histórico dos homens, tornando-os deterministas e implicando, mais gravemente, a redução do futuro ao presente.
\end{abstract}

Palavras-chave: Bertrand Russell. História. Provincialismo. Nacionalismo.

ABSTRACT: The purpose of this article is to offer the historian and also the teacher of history elements that guided the prospect of Bertrand Russell, mathematician and philosopher recognized in the twentieth century, on this field of study. Thus, in the heart of the debate is the "cure of provincialisms" - a term often used by Russell - that the teaching of history can provide to students. For this, there is also the elucidation of a possible dialogue between Russell and Freire with respect to Freire's fears with the fatalism that corrupts the historical sense of men, making them deterministic and involving, more seriously, the reduction of the future to the present.

Keywords: Bertrand Russell. History. Provincialism. Nationalism.

1 Professor de matemática no Colégio Magistra. Participa do Grupo de Estudos e Pesquisas em Etnomatemática (GEPEm) desde 2012. Mestre pela Faculdade de Educação da USP. Tem se interessado por questões que buscam tematizar as dimensões políticas da educação. 


\section{Introdução}

\section{Perspectivas de um matemático insubordinado}

Bertrand Russell, herdeiro de uma longeva tradição familiar aristocrática, rompeu com esta mesma tradição ao declarar aos avós sua decisão de estudar matemática e, daí, filosofia. Com efeito, muitos embates familiares sucederam desde sua primeira declaração e seus avós sentiram-se compelidos a impor uma série de restrições às condições socioeconômicas do neto a fim de que o menino despertasse ao que era, de fato, importante para a manutenção da tradição (RUSSELL, 1958b).

Todavia, Russell nunca se submeteu à tradição. Na verdade, suas posturas diante dos mais variados dilemas caracterizam-se por sua constante insubordinação ao estabelecido. Trata-se, definitivamente, de sua característica mais notável precisamente porque, conforme Russell (1958a) enunciaria posteriormente, o pensamento, por excelência, deve ser revolucionário, anárquico e subversivo - além de sua indiferença com relação ao privilegio, às instituições estabelecidas e aos hábitos confortáveis.

Com efeito, desde sua juventude, Russell não demonstrou a menor distância entre seu discurso e sua prática, de modo que não tardou para que iniciasse seus estudos em Cambridge, onde encontrou o ambiente propício para florescer intelectualmente. Como reconhece diversas vezes, na universidade, fez amizades que manteve durante toda a vida. Em meio às várias discordâncias de ordem filosófica e religiosa que tinha em casa, dedicou-se à matemática por considerar, ainda ingenuamente, que era destituída de conteúdo ético e que, por esse motivo, não suscitaria novas discordâncias com a família, mas, sobretudo, com a avó.

Apesar disso, mesmo em Cambridge, não encontrou as justificativas que esperava desde o primeiro momento de estudos com seu irmão. Em suas palavras, "tardou quase vinte anos para que eu encontrasse toda a justificação que parecia possível, e mesmo isso ficou muito aquém das minhas esperanças juvenis" (RUSSELL, 1958b, p. 4). Entretanto, o estudo da matemática o conduziu ao enfado - um "enjoo pela matemática, resultante de demasiada concentração 
e demasiada absorção pela espécie de habilidade requerida nos exames" (RUSSELL, 1958b, p. 14).

Por esse motivo, quando saiu de seu último exame de matemática, jurou a si mesmo que nunca mais retomaria tais estudos, chegando, inclusive, a vender todos os livros que tratavam sobre o assunto. Depois disso, em suas palavras: "nesse estado de espírito, o estudo da filosofia me proporcionou todo o encanto de uma paisagem nova, quando se sai de um vale" (RUSSELL, 1958b, p. 14). Desde então, ao concluir os estudos em filosofia, tornar-se-ia um eminente filósofo e matemático do século $X X$.

No decorrer de seus estudos em filosofia, contudo, despertou em Russell um interesse ávido pela história. Assim, concomitantemente à graduação em filosofia que obtinha, Russell dedicou-se a um minucioso "exame da história", como chamava. Este exame proporcionou-lhe a constatação de que um modo mais abrangente de compreender a história seria fundamental para promover as mudanças de que, em sua perspectiva, a humanidade necessitava.

\section{Dos provincialismos míopes à compreensão integrada da humanidade}

Russell tornava-se leitor sedento e interessado da história e iniciou seus estudos quando, depois de verificar "a crueldade, a perseguição e a superstição aumentar em grandes saltos", sentiu grande tristeza, da qual gostaria de se desfazer. Tornava-se, ademais, o primeiro matemático eminente de seu século a destacar-se por seus receios e anseios no que se refere à transformação construtiva e democrática da sociedade. Assim, com uma compreensão mais apropriada da história, concluiu que "a loucura é perene, mas que, não obstante, a raça humana sobreviveu", além de que "as loucuras de nossa própria época são mais facilmente suportadas quando vistas tendo em segundo plano as loucuras do passado" (RUSSELL, 1956c, p. 93).

Posteriormente, o que primeiro obteve destes estudos, foi "a sensação de que se é uma gota num grande rio e não uma entidade à parte, estreitamente delimitada". Por esse motivo, defendeu desde então que todo aquele "cujos 
interesses se acham limitados pelo curto espaço de tempo que vai do nascimento à morte, possui uma visão míope e uma limitação de perspectiva que dificilmente poderão deixar de reduzir o alcance de seus desejos e esperanças" (RUSSELL, 1958b, p. 177).

Com efeito, trata-se precisamente da compreensão humanista da história que permitiu a Russell o devido empenho nas polêmicas controvérsias em que esteve envolvido durante a vida, sobretudo no que tange às campanhas pacifistas que empreendeu desde o início do século passado. Por meio da Bertrand Russell Peace Foundation, o matemático reuniu mulheres e homens eminentes de sua época para lutar pela paz.

Dentre as principais polêmicas em que esteve envolvido, destacam-se as tentativas de impedir um desastre nuclear por meio do Manifesto Russell-Einstein - redigido por Russell e assinado por Albert Einstein -, e também a tentativa de incriminar, com o auxílio de Jean-Paul Sartre e Simone de Beauvoir, a cúpula do governo estadunidense pelos Crimes de guerra no Vietnã - tentativa descrita em sua obra de mesmo título em Russell (1967).

Russell soube, portanto, fundamentar sua prática pacifista e indiscutivelmente política em seu minucioso exame da história, de maneira que encontramos no decorrer de sua biografia inúmeros exemplos que demonstram a veracidade desta afirmação. Destarte, inspirados pela leitura das obras de Russell, podemos encontrar vias de enfrentamento dos problemas e perguntas que, sem solução aparente, afligem, atualmente, a sociedade.

Não nego que, de fato, alguns problemas e perguntas tenham mudado e, mesmo aqueles que não mudaram de forma, são proporcionalmente diferentes à medida que o mundo mudou muito nos últimos cem anos. Todavia, conforme defende Russell, existe certa importância na leitura de filósofos que nos precederam e esta "reside em se reconhecer que as perguntas, na maioria, já foram formuladas antes e já receberam, no passado, algumas respostas inteligentes" (RUSSELL, 2003, p. 211).

Deve-se reconhecer, portanto, que seu modo de conceber a história é relevante sob dois aspectos: primeiro, porque grande parte das questões cuja busca de soluções nos aflige hoje já foram respondidas, mesmo que 
parcialmente, por este proeminente filósofo e, segundo, porque seu próprio modo de pensar nos revela características fundamentais da própria atividade do pensamento, de que nunca deveria estar dissociada. Para Russell (1958b, p. 120), como vimos, o pensamento "é anárquico e sem lei, indiferente à autoridade, negligente em relação à sabedoria provada dos tempos", afirmação que reitera e nos demonstra em todos os seus trabalhos.

Primeiro, há de se ressaltar que Russell sempre delegou ao ensino de história a responsabilidade com a desconstrução das certezas consolidadas no tempo e na tradição. Isto porque, a partir do entendimento de que "a certeza absoluta constitui a fonte de muitas coisas más de nosso mundo atual", Russell defende tratar-se de "algo de que a contemplação da história deveria curar-nos", precisamente porque "se verificou que muita coisa considerada como sabedoria se converteu, mais tarde, em insensatez - o que nos sugere que muito da nossa suposta sabedoria não é melhor do que a anterior" (RUSSELL, 1958b, p. 177).

\section{Do nacionalismo exacerbado decorrem os provincialismos}

Ademais, Russell fora um exímio contendor de toda espécie de nacionalismo exacerbado, sobretudo porque compreendia que o sentimento nacionalista e os dogmas que dele decorrem em nada contribuem ao entendimento da humanidade como um todo, ou como dizia, como "espécie biológica engajada em sua sobrevivência". Por isso, para compreender efetivamente seu pensamento político, é necessário, antes, entender que Russell não via motivo racional para a divisão da humanidade em grupos políticos, senão para que uns pudessem impor prerrogativas e privilégios em detrimento de outros.

Sob essa perspectiva, condenou o nacionalismo, sobretudo devido a dois aspectos: por um lado, porque "um mundo cheio de patriotas pode ser um mundo pleno de discórdia" e, por outro, porque "quanto mais intensamente uma nação crê em seu patriotismo, tanto mais fanaticamente indiferente se torna ao mal sofrido pelas demais". 
De maneira introdutória, sua opinião sobre o nacionalismo deve ser esclarecida de acordo com dois pontos de vistas distintos: o cultural e o político. Sob o ponto de vista cultural, Russell (1970, p. 107) considerava que "uma das realidades mais tristes do mundo moderno é a sua extraordinária uniformidade" e que o nacionalismo era louvável por permitir a diversidade - na literatura, nas artes, nas línguas e em todos os outros âmbitos de caráter cultural. Entretanto, sob o ponto de vista político, Russell defendia "não haver uma só palavra que se possa dizer em seu favor".

Assim, embora o substrato de toda crítica russelliana ao nacionalismo seja a substituição da preocupação com o bem da humanidade pela preocupação com o bem apenas de uma nação, é necessário estudar mais detidamente sua interpretação desse sentimento que, conforme Russell entende, é algo bom em essência, mas que, devido às distorções ideológicas do capitalismo, torna-se deletério.

O nacionalismo, portanto, em consonância à perspectiva do filósofo, que surge do amor pela terra natal e do orgulho pelos feitos históricos dos compatriotas, não deve ser reprovado. Deve-se compreender, aliás, como Russell (1956a, p. 97), que "a raiz desse sentimento é, em parte, geográfica e, em parte, biológica". Todavia, não devemos ingenuamente confundir esta compreensão com o que se manifesta correntemente em nome do nacionalismo: afinal, "esse sentimento primitivo não é, em si mesmo, político ou econômico" e manifesta-se "pelo próprio país e não contra outros países". Em outros termos, o nacionalismo é prejudicial "se não é tanto o amor pela terra e pelos compatriotas quanto o é o ódio pelos países estrangeiros".

Mais gravemente, para Russell (1962), a divisão da humanidade em nações e o estímulo ao nacionalismo provocaram grandes deformações nos juízos nacionais: toda nação dedica, comumente, honrarias públicas (como estátuas, prêmios e nomes de instituições) aos homens que reconhecidamente demonstraram sua habilidade em matar estrangeiros durante conflitos. Evidentemente, trata-se de homenagens a que dificilmente um estrangeiro poderia atribuir qualquer valor. A fim de exemplificar seu entendimento, Russell (1962, p. 6) afirma: 
Nós, na Grã-Bretanha, dedicamos os nossos mais imponentes monumentos públicos a Nelson e Wellington, a quem honramos por sua habilidade em matar estrangeiros. Por mais estranho que pareça, os estrangeiros não sentem a mesma admiração que nós pelos britânicos que revelaram essas espécies de habilidade. Se perguntássemos a qualquer indivíduo culto não britânico quais eram, em sua opinião, as maiores glórias da Grã-Bretanha, era muito mais provável que ele, ao invés de Nelson e Wellington, se referisse a Shakespeare, Newton e Darwin.

O excerto anterior esclarece, assim, que o nacionalismo é responsável por muitas das piores distorções morais que nos acometem, quando manifestamos nosso apoio a certa nação em detrimento do bem-estar de toda a humanidade ou, acima de tudo, quando glorificamos o bem de determinada nação frente à miséria do restante do planeta.

Ademais, de acordo com a concepção da história de Russell (1951, p. 69), tornou-se também mais evidente que "todo país ensina história de maneira a inclinar os jovens a pensar que seu próprio lado tem certeza da vitória e, portanto, aumenta a propensão à guerra, que quase sempre excede o que é racional". Tais constatações o permitiram compreender que "o nacionalismo é, em nossos dias, o principal obstáculo à extensão da coesão social além das fronteiras nacionais" e, portanto, "a principal força a favor do extermínio da raça humana" - motivo suficiente para desencorajar as formas de nacionalismo que, ao invés de reconhecer as ações construtivas de seu próprio país, promovem o ódio e o preconceito aos demais.

É fundamental, portanto, identificar a contradição que reside no substrato do nacionalismo enquanto sentimento de aversão ao outro: afinal, "todos concordam que o nacionalismo de outros países é absurdo, mas o nacionalismo de seus próprios países é nobre e esplêndido, e qualquer um que não o sustente é um vira-lata covarde" (RUSSELL, 1951, p. 69).

Em vista disso, Russell (1956a, p. 99) - para quem o nacionalismo exagerado "é indubitavelmente o mais perigoso dos males de nossos tempos" defende, resoluto, que o mesmo devia ser considerado "como sendo uma forma de histeria coletiva a que os homens estão, infelizmente, sujeitos, e contra a qual precisam fortalecer-se intelectual e moralmente". É possível compreender, a partir da perspectiva russelliana, que esta forma de nacionalismo exacerbado 
não é compatível, sobretudo, com sua compreensão da humanidade como um todo e com uma concepção crítica da história,

A crise que permite o conceito de nacionalismo, conforme enuncia Russell (1958a, p.37) se deve à constatação de que "o nacionalismo não convém como credo porque não possui qualquer universalidade". Mais especificamente, é o componente do orgulho nacional que, na prática, "envenena o patriotismo e o torna inferior, como religião, às crenças que visam à salvação de toda a humanidade". Em síntese:

Não podemos impedir-nos de ter maior amor pelo próprio país do que pelos demais. Nem há razão para que desejemos evitá-lo, como não há para que devamos amar igualmente a todos os homens e mulheres. Qualquer religião adequada, porém, nos levará a temperar a desigualdade de afeição pelo amor da justiça, e a universalizar nossos objetivos pela compreensão dos objetivos comuns do homem.

Deve-se reconhecer a convicção de Russell de que "quando os homens tiverem aprendido a subordinar seu próprio bem ao bem de um todo mais amplo, não poderá haver qualquer razão válida para conter a raça humana" (RUSSELL, 1958a, p. 37). Trata-se, de fato, de uma convicção que o matemático desejava ver construída por meio da educação, conforme afirma no seguinte excerto:

Penso que no programa educacional devemos insistir no princípio de que a humanidade é uma família com interesses comuns portanto a cooperação é mais conveniente do que a rivalidade, e amar o próximo é, não só um dever moral normalmente inculcado nas aulas de religião, mas também o melhor caminho a seguir para alcançar a felicidade própria. (RUSSELL, 1970, p. 177)

Ademais, Russell (1970, p. 179) fundamentava sua convicção na premissa de que devemos "aceitar a ideia de que o nosso vizinho também tem direito a ser feliz, se nós próprios queremos ser felizes" e esperava, assim, que cada homem e cada mulher pudessem compreender que "o indivíduo não é o fim e o objetivo de sua própria existência": além do indivíduo, como explica, existe a comunidade e o futuro da humanidade (RUSSELL, 1958a, p. 140). 
Considero, acima de tudo, que sua intenção basilar era promover uma superação do sentimento de nacionalismo exacerbado, que vigorava e fora causa dos mais terríveis desmandos de sua época, e sua consequente substituição pelo amor à humanidade, capaz de evidenciar a irracionalidade dos motivos de quaisquer guerras, desencorajando-as. Com isso, Russell (1956b, p. 228) determinou que, a fim de superar o despautério da guerra e do nacionalismo por meio da educação - e, mais especificamente, do ensino de história -, "o conceito em mira será o da raça humana como um todo, a lutar contra o caos externo e a cegueira interna, com a débil luz da razão a desenvolver-se em fanal". Assim, toda forma de divisão deveria ser confrontada: "a divisão entre raças, nações e credos deve ser apresentada como loucuras que nos distraiam da luta contra o caos e as trevas, pois que essa luta constitui a atividade humana essencial".

E mais, da constatação russelliana de que muito da educação de sua época foi usado para glorificar a guerra, Russell depreende que "a história devia versar mais sobre o mundo em geral do que sobre um país em particular e devia salientar mais as questões de importância cultural do que as guerras", de modo que, quando seu estudo for inevitável, "não devem ser ensinadas somente sob o ponto de vista do vencedor e dos feitos históricos" (RUSSELL, 1956a, pp. 100101). Durante este estudo, conforme acrescenta Russell, o educando "deve meditar sobre o campo de batalha com os seus feridos, sentir a angústia dos que ficaram sem lar nas regiões devastadas e conhecer todas as crueldades e injustiças para as quais a guerra oferece oportunidades".

Em vista disso, Russell afirma que um ensino mais apropriado da história pode ser a medida certa para o enfrentamento dos diversos problemas que encontra no modo de viver de seu século e evidencia que "as escolas deverão ensinar, não a estreita e enviesada história que tem sido, até agora, frequentemente suficiente, mas a história do mundo de um ponto de vista imparcial" (RUSSELL, 1951, p. 146).

O filósofo defenderia ainda que "o comportamento entre iguais é o que ela [a criança] mais precisa aprender. Muitas das desigualdades existentes no mundo são artificiais e será uma boa coisa que a criança as ignore" (RUSSELL, 1956b, p. 157). Constitui desafio provocador, portanto, refletir em que medida o 
ensino de história pode pavimentar um caminho profícuo dos provincialismos à humanidade, isto é, os mesmos resultados que Russell esperava de um ensino adequado da história.

$\mathrm{Na}$ verdade, esta proposição fundamenta-se na declaração russelliana de que o ensino de história poderia ocorrer em ampla maioria a partir do cinema, ou, mais atualmente, a partir das mídias de comunicação em geral. Afinal, o ensino de história, iniciado por meio do cinema, torna-se apropriado para

\footnotetext{
curar o provincialismo no espaço e tempo e fazer com que as crianças percebessem que o verdadeiro ser humano, com sentimentos reais, pode ser externamente bastante diferente das pessoas entre as quais elas vivem, mas interiormente é composto pelo mesmo material humano. (RUSSELL, 1951, p. 205)
}

Não há, portanto, como negar que parte considerável dos provincialismos míopes de que tratamos decorre das distorções que acometem o sentimento nacionalista, transformando-o orgulho em preconceito. Historiadores e professores de história devem, então, conscienciosos desta decorrência, evitar quaisquer estímulos desnecessários ao nacionalismo e às correntes tradicionais estreitas do ensino da própria história.

\section{O ensino de história e a simpatia abstrata}

Em outra instância, o ensino de história, para o filósofo, também se apresenta como um caminho para a gestação e desenvolvimento de sentimentos construtivos, sobretudo no que se refere, evidentemente, aos outros. Isso porque, conforme ponderava Russell (1956b, p. 59), "podemos sentir simpatia por um sofrimento vivamente pintado num romance, como podemos comovernos com uma simples menção estatística" - capacidade que denominou simpatia abstrata. Para Russell, constantemente nos sensibilizamos ao conhecer uma criança que padece de uma grave patologia ou ao conhecer indivíduos com patologias em estágio terminal, mas dificilmente nos sensibilizamos com a 
menção do número de vítimas de determinada epidemia ou de certo conflito bélico.

Essa sensibilidade, denominada simpatia abstrata, é violada constantemente, para não mencionar seu contínuo desgaste junto ao senso moral das pessoas. O empreendimento a que deu início a publicidade, à época de Russell, hoje se encontra no auge e com isso pode-se esperar pouco ou nada do desenvolvimento da simpatia abstrata - isto é, da capacidade do ser humano de se sensibilizar com a dor alheia.

Para Russell (1956b, p. 59), o mesmo ocorre com a guerra: "em geral julgamo-la horrível quando temos um filho ou irmão mutilado, mas não a julgamos um milhão de vezes mais horrível pelo fato de mutilar milhões de seres humanos". Afinal, nossa capacidade de simpatia abstrata foi desbastada junto ao nosso senso moral pelas barbaridades que nos são apresentadas de modo muito natural todos os dias.

Todos estes fenômenos, tão comuns, são devidos ao fato de que a simpatia, segundo o filósofo, não nasce na maior parte das gentes por força apenas do estímulo abstrato. Entretanto, "uma grande proporção dos males modernos cessaria se aumentássemos a nossa simpatia abstrata", assegura. Mais grave é a constatação mais abrangente que "a ciência muito acresceu o nosso poder de afetar a vida dos povos distantes, sem que aumentasse a nossa simpatia por eles" (RUSSELL, 1956b, p. 60).

A educação, e mais especificamente o ensino de história, precisa se comprometer com a responsabilidade diante desse cenário: a construção e a ampliação de condições para o aprimoramento de nossa capacidade de simpatia abstrata. E, para isso, é fundamental que a compreensão russelliana da humanidade como um todo oriente esse comprometimento.

Lembro-me, aliás, da orientação que Russell dá ao ensino de história sobre as guerras: o filósofo nos diz que os educandos devem refletir sobre a dor dos feridos, a miséria das famílias e as inconsoláveis injustiças acometidas aos inocentes. O mesmo ocorre no caso da simpatia abstrata: as escolas e os educadores devem, ao invés de corroborar o desgaste do senso moral e da 
sensibilidade, se sentir responsáveis pela criação de condições férteis para o desenvolvimento da simpatia abstrata.

Consideremos, portanto, que o devido ensino de história deve assumir como propósito predominante "curar o provincialismo no espaço e tempo" e, com isso, "fazer com que as crianças percebessem que o verdadeiro ser humano, com sentimentos reais, pode ser externamente bastante diferente das pessoas entre as quais elas vivem, mas interiormente é composto pelo mesmo material humano" (RUSSELL, 1951: 205). Trata-se, evidentemente, do referido caminho dos provincialismos à humanidade que o ensino de história pode pavimentar por meio do estímulo à simpatia abstrata.

\section{Por um ensino de história insubordinado!}

Ademais, é importante que nossos educandos compreendam em que momento histórico são inseridos, quando trazidos ao mundo. Mais relevante, portanto, é a constatação de que, por meio de uma concepção crítica e abrangente da história como a de Russell, torna-se possível pensar no momento em que os educandos chegam à escola e sua educação precisa estar inserida nas considerações daquilo que fora realizado e também daquilo que precisa ser feito. O ensino de história, orientado por tais considerações, dialoga constantemente com as problemáticas em que se debatem as mulheres e os homens em seu tempo histórico correspondente.

Ademais, a história, como vimos, tornou-se objeto de incessantes disputas desde que se constatou que sua compreensão poderia proporcionar resultados que dependiam intimamente das maneiras como a história seria contada. Como observamos nas leituras de Russell, contar a história sob a perspectiva dos dominantes não é neutro: ao invés disso, reitera determinada compreensão do homem, das raças e das etnias, dos gêneros... Compreensões que permitem, evidentemente, que a dominação persista. Insubordinar-se ao estabelecido significa, então, contar e ouvir outras histórias distintas das hegemônicas que permitam aos educandos, além da compreensão da humanidade como um todo, 
o entendimento de que as desigualdades são produtos de sucessivas construções históricas e, precisamente por isso, são passíveis de desconstrução.

Uma perspectiva mais abrangente da história também se mostra fundamental para desenvolver epistemologias mais apropriadas às correções que uma autêntica justiça cognitiva demanda². Existem, evidentemente, muitas correções fundamentais para que o currículo escolar abandone, de uma vez, a perspectiva do opressor e disserte mais sobre o flagelo dos oprimidos. Não se trata, é óbvio, de um currículo "vitimista", mas de um currículo que não reitera as desigualdades artificiais, nem é omisso às injustiças históricas cometidas contra determinadas comunidades.

Com efeito, o filósofo considera, sob a mesma perspectiva, sobremodo difícil manter estável uma situação de desigualdade declarada em que poucos concentram muito poder - propriedade, capital e acesso aos meios de produção e de representação -, enquanto muitos possuem pouco ou nada disso. À educação e, evidentemente, ao ensino de história, Russell (1957a, p. 125) atribui uma enorme parcela de responsabilidade pela manutenção de tal estabilidade, reconhecendo que existem "inúmeras maneiras por que a educação, em vez de propiciar conhecimento verdadeiro, é engendrada para tornar o povo dócil à vontade dos seus amos".

Mais gravemente, complementa sua denúncia com a constatação de que "sem um complicado sistema de fraude nas escolas primárias seria impossível conservar a camuflagem de democracia". Sob essa perspectiva, é fundamental, para Russell (1956b: 169), desvelar que "tem sido o costume da educação favorecer o próprio Estado, a própria religião, o sexo masculino e os ricos" - aos quais acrescentaríamos, sem dúvidas, os brancos, os heterossexuais e tantos outros segmentos da sociedade que constituem a normatividade prescrita nos discursos e ideologias hegemônicos.

O ensino de história que, devidamente, acompanhe o caminho que parte dos provincialismos míopes rumo à compreensão mais ampla da humanidade não

\footnotetext{
2 Para um aprofundamento nesta temática, recomendo a leitura de SANTOS, Boaventura Souza, MENESES, Maria Paula. (orgs.) Epistemologias do Sul. São Paulo: Editora Cortez, 2010. Também recomendo a leitura de Valle (2014c): um artigo orientado pela proposição: em que medida e com que profundidade a história oral pode ser fundamental na construção de uma possibilidade de justiça cognitiva no currículo.
} 
pode se omitir diante deste costume conservador. Deve, ao invés disso, insubordinar-se às práticas e aos discursos que pretendem legitimar ou favorecer o status quo, do mesmo modo como Russell insubordinou-se à sua época.

\section{Do ensino de história à educação: uma ampliação do debate}

Não obstante, Russell reconhece que a educação é utilizada, perniciosamente, como um meio para inculcar credos e valores que servem a propósitos distintos daqueles que pretendem transformar a sociedade. Em tal reconhecimento, refere-se, sobretudo, aos estímulos ao nacionalismo e, resoluto, afirma que "se todos os governos ensinassem a mesma tolice, o mal não seria tão grande. Infelizmente, cada qual tem a sua própria marca de estupidez, e tal diversidade serve para produzir hostilidade entre os devotos de credos diversos" (RUSSELL, 1956c, p. 123).

Ademais, a educação tem inculcado, não raramente, hábitos mentais igualmente perniciosos como obediência, disciplina, desprezo para com grupos distintos, aceitação passiva da sabedoria do professor e, sobretudo, a aquiescência à dureza na luta pelo êxito mundano. Sobre tais hábitos, Russell (1958a, p. 112) afirma, convicto, que são contrários à vida e que, portanto, todos devem ser substituídos:

\footnotetext{
Em lugar de obediência e disciplina, deveríamos visar à preservação da independência e do impulso. Em lugar da dureza, a educação deveria procurar desenvolver uma maneira justa de pensar. Em lugar do desprezo, deveria inculcar o respeito e o esforço de compreensão; em relação à opinião dos outros, deveria gerar, não necessariamente, aquiescência, mas apenas aquela oposição combinada com a apreensão imaginativa e uma compreensão clara dos fundamentos para a oposição. Em lugar de credulidade, o objetivo deveria ser estimular a dúvida construtiva, a paixão da aventura mental, o sentimento de mundos a conquistar pelo empreendimento e pela ousadia do pensamento.
}

Deve-se dedicar atenção especial à referida substituição porque, conforme defende o autor, as causas imediatas desses males são a satisfação com o status quo e a subordinação do aluno individual a fins políticos perversos, devido à 
indiferença que denota em relação ao conhecimento. É fundamental, portanto, que os alunos se tornem conscientes da interdependência dos diferentes grupos de homens e associem tal consciência com a importância da cooperação e com a ignorância do conflito.

Para Russell (1951, p. 147), em uma palavra, "as crianças deviam ser trazidas a tornarem-se cidadãos do mundo no qual têm de viver, não no mundo daqueles séculos intolerantes em meio aos quais a cultura acadêmica adora habitar". Evidentemente, não se trata de preservar os alunos ignorantes do passado: a educação deve, no que se refere ao passado, permitir o reconhecimento de que nosso mundo apresenta, hoje, diferentes credos, desejos e aptidões com relação àqueles que foram requeridos em épocas tecnicamente mais simples.

Sob a perspectiva apresentada nos parágrafos anteriores, o filósofo defende, portanto, que a educação nunca pode ser deixada sob a responsabilidade apenas da Igreja, do Estado, do professor ou dos pais. Afinal, cada qual se utiliza da educação em vista de propósitos distintos que vão desde o apoio à forma política vigente até o incentivo à competição deliberada, de modo que, conforme desvela Russell (1957a, p. 151), "a própria criança, como finalidade em si, como ser humano autônomo, com direito à felicidade e ao bemestar possível não entra em cogitação". Não obstante, o autor acrescenta que, desafortunadamente, "a criança carece da experiência necessária para orientar a própria vida, e é, portanto, presa nos sinistros interesses que se prevalecem da sua inocência", e conclui: "É isto que faz a dificuldade do ensino um problema político".

Enfaticamente, Russell (1957a, p. 159) dirá, por esse motivo que:

Nenhum homem está apto a educar a menos que sinta em cada aluno um fim em si, com seus direitos e sua personalidade, não apenas uma peça num quebra-cabeças, ou um soldado num regimento, ou um cidadão num Estado. A reverência pela personalidade humana é o início da sabedoria em todas as questões sociais, mas principalmente na educação.

Russell (2009) esclarece, dessa maneira, que capitalistas, militaristas, eclesiásticos e os demais obscurantistas são amplamente beneficiados quando 
há, na educação, a influência de qualquer credo, superstição ou carência de julgamentos críticos; porém ressalta que o poder de toda espécie de obscurantismo depende essencialmente da prevalência da emoção e por isso uma das metas basilares da educação tem sido curar as crianças do mau hábito de pensar.

Por esse motivo, justifica que, se dirigisse a educação, "exporia as crianças aos defensores mais veementes e eloquentes de cada um dos aspectos de cada questão típica", a fim de tornar possível que toda criança adquirisse certa "imunidade quanto à eloquência", que considera fundamental para os cidadãos de uma democracia (RUSSELL, 1957b: 252).

Em decorrência disso, Russell (2003: 102) desvela sua própria concepção de educação: "educação, pois, é aprender a pensar por si sob a orientação de um professor". Deve-se acrescentar, para compreender amplamente como Russel concebe a educação, que "aprender a pensar por si sob a orientação de um professor" somente é possível por meio da educação que "acompanha a direção dos próprios interesses instintivos da criança, fornecendo o conhecimento que tem em mira, e não áridas e pormenorizadas informações, inteiramente sem relação com os seus desejos espontâneos" (RUSSELL, 1955, p. 206). Reiterando, assim, suas convicções, Russell (1956b) declara que o espontâneo desejo de aprender deve tornar-se o pivô da educação.

Existem, todavia, muitos fatores que impedem que a educação seja orientada pelos princípios que Russell defende, dentre os quais destaco, principalmente, a constatação de que o professor se transformara "num servidor cortês obrigado a executar as ordens de homens que não têm a sua cultura, não dispõem de experiência quanto ao trato da juventude, e cuja única atitude com respeito à educação é a de um propagandista" (RUSSELL, 1956c, p. 145) 3 .

\footnotetext{
3 Russell (1957a: 143) descreve, de maneira mais abrangente que isto não ocorre apenas na educação: "Os mestres, pelo contato com as crianças, vêm a compreendê-las e cuidá-las, mas são controlados por autoridades sem experiência prática para as quais as crianças talvez não passem de guris malcriados. Portanto, são em geral nocivas as interferências da autoridade com a liberdade dos mestres. É o mesmo em tudo: o poder está nas mãos daqueles que controlam as finanças, não dos que conhecem aquilo com o que se deveria gastar o dinheiro. Assim, os detentores do poder são, em geral, ignorantes e malévolos, e quanto menos exercerem seu poder, melhor".
} 
Existe, de fato, como Russell (1956c, p.148) acertadamente pontua, um controle bastante rígido sobre os procedimentos que são permitidos aos professores: "enquanto tal homem estiver apenas ensinando o alfabeto e a tabuada, os quais não despertam controvérsias, os dogmas oficiais não deturpam, necessariamente, a instrução por ele ministrada". Restringem-se, portanto, as possibilidades de oferecer uma educação verdadeiramente crítica, no sentido que o filósofo encoraja.

Há de se concordar com a afirmação de Russell (1957a, p. 176) de que "a produção é mais barata quando é uniforme e em larga escala do que quando é dividida em um número de pequenas unidades" e, embora perniciosamente, tal afirmação aplica-se exatamente na mesma medida tanto à produção de alfinetes como à produção de opiniões e, portanto, à educação. Russell desaprova declaradamente qualquer medida que, aplicada à educação, decorra do princípio enunciado, porque entende que da produção em larga escala de opiniões uniformes só pode derivar o conservadorismo.

Afinal, "o conservadorismo não exige nenhum de tais altos processos mentais. O partidário da mudança radical, ao contrário, deve ter certo grau de imaginação a fim de poder conceber algo diferente do que existe" (RUSSELL, 1956a, p. 11). Sob essa perspectiva, o autor (1956b, p. 269) defende, de modo bastante lúcido e destoante do que costuma ocorrer contemporaneamente que "o importante não é aumentar a soma do que é hoje ensinado às crianças e sim inocular-lhes o espírito de aventura e liberdade, o senso de estar numa viagem de descobertas".

Em vista disso, Russell conjectura que seja possível, por meio da educação, aplacar os impulsos negativos que assolam a humanidade, de modo a promover, com o conhecimento que a psicologia e a sociologia possuem, uma autêntica difusão de sentimentos positivos. No entanto, sem demonstrar qualquer ingenuidade, Russell (1977, p. 146) reconhece que, na realidade, "a inteligência tem sido empregada não para aplacar as paixões, mas para exacerbá-las". De fato, esse reconhecimento respalda-se no fato de que, historicamente, "o poder tem sido empregado para dar aos fortes uma parcela maior e indevida das coisas boas e para deixar aos fracos uma vida de canseira e miséria". Trata-se, 
indiscutivelmente, de um caminho necessário a percorrer que supere tais provincialismos rumo ao entendimento pleno de nossa humanidade.

\section{Russell e Freire: um diálogo necessário sobre a história}

A coerência entre o discurso e a prática que reconhecem o protagonismo ativo dos alunos como elemento essencial à educação foi evidenciada, depois de Russell, por um dos mais proeminentes educadores populares brasileiros da contemporaneidade: Paulo Freire. Notável, no entanto, é a constatação de que, em muitos sentidos, outros dos princípios defendidos por Russell para a educação foram reafirmados pelo educador. Freire, de acordo com sua profícua vivência política na educação, pôde aprofundar-se em questões que, apesar de seu provável desconhecimento, haviam sido delineadas previamente por Russell. ${ }^{4} \mathrm{O}$ educador foi responsável, assim, por reconfigurar o panorama das discussões sobre educação, não apenas no Brasil, mas em muitos outros países com os quais teve contato.

Logo, devido precisamente ao significado inestimável e determinante que toda a vida e a obra de Paulo Freire adquiriram para o cenário brasileiro, dedicome a evidenciar como as perspectivas de Russell sobre a educação aproximaram-se dos conceitos e reflexões que o educador brasileiro apresentaria posteriormente. Proponho, então, que iniciemos este exame a partir da forma como Russell concebe a própria prática educativa.

Afinal, ao defender que a educação não deve se tornar mecanismo de inculcação de credos e valores que privilegiem determinados grupos de indivíduos e nem deve padecer da impregnação dos hábitos provenientes de nosso sistema econômico, Russell confronta-se com a ideologização que mais tarde Freire (1982) denunciaria. Evidentemente, ambos examinaram a educação enquanto uma possibilidade de clarificar a realidade, um meio de desobscurecer as ideologias que permitem o conservadorismo. Depreende-se daí uma marca

\footnotetext{
4 Sobre tais consonâncias, recomendo a leitura de Silva e Valle (2014) em que se torna possível constatar a convergência das conceituações de ambos à ideologia perniciosa do mérito em que se fundamenta a meritocracia atual.
} 
notável em que se complementam o pensamento de Russell e Freire: seu profundo descontentamento com o capitalismo e com as injustiças que perpetua.

Sob a perspectiva enunciada, a primeira aproximação que devo abordar consiste no papel do professor frente à educação, porque, para ambos, é necessário compreender que o ensino não é apenas um processo de transmitir informação e, para Russell (2003, p. 101), como Freire defendeu singularmente depois, o ensino de determinados conteúdos "não é a única função do professor, nem a mais importante". Afirmo, portanto, que um primeiro ponto em que coincide o pensamento destes dois homens reside na própria concepção da prática docente: "o papel do professor é de orientador, de levar o aluno a ver por si mesmo".

Não tardou, assim, para que ambos descobrissem que só é possível para um professor "levar o aluno a ver por si mesmo" quando este professor considera seu aluno com o devido respeito e, sobretudo, com grande afeição e estima. É preciso reconhecer o aluno, estimá-lo. Russell censurou, não poucas vezes, todas as atividades educativas em que notava a ausência da consideração pelo aluno, de maneira que, quando Freire (1997, p. 110) afirma, sobre os educandos, que "é escutando que aprendemos a falar com eles".

Todavia, no que tange ao possível - mas necessário - diálogo entre Russell e Freire, destaco o receio de ambos com as compreensões fatalistas e deterministas da história. Este, talvez, seja o elemento em que ambos apresentam, como veremos, maior convergência.

"O mundo em que nos encontramos é tal que grandes esperanças e receios desanimadores justificam-se igualmente pelas possibilidades", dizia Russell (1977, pp. 18-19), reiterando a compreensão de que, de fato, "os receios são muito amplamente sentidos e tendem a produzir um mundo de indiferente melancolia", mas as esperanças, acresce o matemático, "implicam imaginação, coragem, e são menos vívidas nas mentes da maioria dos homens". Com efeito, Russell considerava que somente porque não são vívidas que parecem utópicas de maneira que "o que existe é tão-somente uma espécie de indolência mental". Sobrepujar esse estado de indolência mental configura-se, portanto, como nossa 
responsabilidade basilar - como responsabilidade basilar de um ensino de história comprometido com a "cura dos provincialismos".

Há de se reconhecer, então, que sustentando a indolência mental a que se refere Russell está precisamente o fatalismo com que muitos encaram a história: um discurso e uma prática deterministas e imobilizadores da história. Afirmar que a transformação construtiva, a paz e a democracia não são possibilidades em nosso horizonte não é "o discurso da constatação da impossibilidade, mas o discurso ideológico da inviabilização do possível" (FREIRE, 2014, p. 45). Um discurso reacionário ou desesperadamente fatalista, argumenta o educador, sustentado somente por quem "aceitou a acomodação, inclusive por lucrar com ela".

De fato, não há fatalismo na compreensão russelliana da história, sobretudo porque, como vimos, Russell após muitos anos de estudo, aprimorou uma concepção bastante crítica da história. A acomodação, ou indolência, representa, então, uma distopia: "a expressão da desistência da luta pela mudança". Falta a quem se acomoda, elucida Freire (2014, p. 45) "a capacidade de resistir". Afinal, trata-se de empreendimento sobremodo mais fácil a quem deixou de resistir alinhar-se ao discurso da impossibilidade "do que assumir a briga permanente e quase sempre desigual em favor da justiça e da ética".

Torna-se, ademais, nossa responsabilidade como historiadores $\mathrm{e}$ professores de história convencer-nos e aos educandos de que "por grande que seja a força condicionante da economia sobre o nosso comportamento individual e social, não posso aceitar a minha total passividade perante ela" (FREIRE: 2014, p. 63). Isto para não reproduzir as distorções sistêmicas que impregnaram a educação e o cotidiano de educadores e educandos. Por isso, assumir nossa responsabilidade com a "cura dos provincialismos" demanda o reconhecimento de que não somos inteiramente condicionados por nossa história, mas de que, sobretudo, a escola não somente reproduz o velho, mas pode também produzir o novo - e, assim, insubordinando-se à tradição, obliterar preconceitos hereditários, enfatizar a cooperação em detrimento da competição...

Nossa politicidade termina se consideramo-nos condicionados e impotentes, ensina-nos Freire. Precisamente, por esse motivo, "aqueles que aspiram a uma 
reconstrução socioeconômica que não há de se completar no dia de amanhã devem, para ter alguma chance de sucesso, ser capazes de abordar seus objetivos por etapas", recomenda Russell (2001, p. 40). Isto porque dessa maneira retificamos nosso interagir com o mundo e nossa capacidade de mudar e de mudá-lo. Afinal, como complementa o filósofo (2001, p. 41), "são necessárias atividades que eduquem as pessoas para esses objetivos finais, mas também deve haver realizações num futuro próximo e não simplesmente uma vaga esperança do paraíso distante". Nossa responsabilidade desvela-se, portanto, em instilar em todo educando o sentimento de que a transformação da sociedade que desejamos depende, e muito, de nós mesmos.

Evidentemente, nossos autores não se entregaram à ingenuidade; orientaram-nos, ao invés disso, à constatação de que "o poder dominante, entre muitas, leva mais uma vantagem sobre nós: o ardil ideológico de que se acha envolvida a sua mensagem na mídia" (FREIRE, 2014, p. 127). Como vimos, nosso propósito torna-se fundamentalmente, então, desmistificar as ideologias abstrusas que governam a realidade, obstaculizando uma leitura crítica do mundo.

Evidência disto é a morte do sonho e da utopia com que se preocupa Freire. Para o educador brasileiro, ambas decorrem da morte da história, representada por sua compreensão fatalista. Tudo isto implica, conforme argumenta Freire (2014, p. 142), "na redução do futuro à permanência do presente" permanência capaz de agravar as crises e as contradições do capitalismo.

Com efeito, para Russell (2001, p. 42-43), a morte do sonho e da utopia se vincula estritamente ao progresso do sistema capitalista e o agravamento de suas crises e suas contradições que, em parte reiteradas por tais distopias, também as reiteram. Por isso, para o filósofo, tornou-se imprescindível conscientizar de que nossas instituições podem ser transformadas, mas "a dificuldade que existe é meramente a de infundir nos homens esperança, imaginação suficiente para verem quão desnecessários são os males de que padecem e a compreensão sobre a forma de debelar esses males". Em seus escritos, tornou-se notável, então, seu receio com a morte do sonho e da utopia, representados pela esperança que desejava infundir na humanidade. 
A humanidade deveria, para Russell, ser orientada à constatação de que "a propriedade privada da terra e do capital não é defensável nem em termos de justiça nem como modo econômico de produzir aquilo de que a comunidade precisa" - sobretudo porque tolhe a vida de homens e mulheres, cultivando neles toda sorte de impulsos de posse e a "veneração do sucesso". ${ }^{5}$ Em seus termos, o filósofo defendia que "a ação revolucionária pode ser desnecessária, mas são indispensáveis o pensamento revolucionário e, produto do pensamento, uma esperança racional e construtiva". Essa esperança permite a construção de outras utopias e, permeando tais construções, sempre há a convicção de que podemos mudar nossa história. Trata-se, definitivamente, de pautas que em muito se relacionam ao ensino da história na forma como consideramos anteriormente.

Com efeito, o fatalismo como compreensão da história da humanidade consiste, talvez, no maior e também mais pernicioso "provincialismo de tempo e de espaço" de que a educação e o ensino da história precisam nos curar. Isto porque, como vimos, este provincialismo, mais do que os anteriores, torna-se imobilizador das práticas e discursos progressistas, retém a transformação, mas, ainda mais gravemente, reduz nosso futuro à permanência do presente. Curarnos do fatalismo que permeia as interpretações mais estreitas da história é necessário e urgente, portanto.

\section{Para (não) concluir...}

O propósito deste texto consiste, sobretudo, na elucidação dos elementos de maior destaque da obra russelliana sobre a história e seu ensino, capazes de nos oferecer a cura dos provincialismos mais perniciosos que afligem a humanidade. Entretanto, deve-se notar que existem muitas outras perspectivas

\footnotetext{
5 Russell (2001, p. 40) demonstrava consciência de nossas dificuldades no enfrentamento do sistema capitalista ao ponderar que "a linha demarcatória entre o capitalista e o assalariado não é clara, como a linha entre turcos e armênios ou entre um inglês e um hindu. Os defensores da revolução social têm se equivocado em seus métodos políticos, principalmente porque não se deram conta da quantidade de pessoas cujas simpatias e interesses estão metade no lado do capital, metade no lado do trabalho. Essas pessoas tornam muito difícil uma política revolucionária bem definida".
} 
que contribuem com este debate, como é o caso, evidentemente, da perspectiva freireana. ${ }^{6}$ Precisamente por esse motivo, não há um meio de encerrar o debate acerca da temática introduzida neste artigo e, assim, resta-nos sempre o desafio de concluir uma redação sem pretender extirpar, no momento de sua publicação, a problemática denunciada.

Assim, para (não) concluir, permito-me a seguinte indagação: como e em que medida as outras áreas do saber acadêmico contribuem ou não para a cura dos referidos provincialismos de tempo e de espaço? A busca por respostas a esta indagação permitirá certamente que encontremos caminhos teóricos e práticos para o enfrentamento, ou a cura como chamava Russell, de tais provincialismos - do silenciamento do outro, da compreensão distorcida da história e da humanidade, dos fatalismos e determinismos que rondam as interpretações em história...

"Um diagnóstico correto é, necessariamente, o primeiro passo para a cura", dizia Russell (1955, p. 171). Torna-se necessário, portanto, identificar, diagnosticar em que profundidade cada uma das disciplinas e das áreas de saber permanecem impregnadas dos provincialismos para que a cura se torne possível em nosso horizonte. Considero, com Russell, que certamente descobriremos que muitas práticas e discursos devem ser abandonados e, em outros, descobriremos a urgência de colocá-los em atividade.

O ensino da história pode contribuir, como desejava Russell, com a cura dos provincialismos e instilar nos homens a devida compreensão da humanidade como um todo e, mais, de uma humanidade não condicionada pela história. Basta, para tanto, que, conscienciosos destes e de outros debates acerca desta mesma temática, historiadores e educadores unam-se neste mesmo propósito.

\section{Referências}

FREIRE, P. Ação cultural para a liberdade. Rio de Janeiro: Paz e Terra, 1982. Pedagogia da Autonomia. Rio de Janeiro: Paz e Terra, 1997.

\footnotetext{
6 Para o exame de outras perspectivas consonantes às de Russell, recomendo a leitura de Valle (2015).
} 
Pedagogia da indignação: cartas pedagógicas e outros escritos. São

Paulo: Paz e Terra, 2014.

RUSSELL, Bertrand. New hopes for a changing world. Londres: George Allen \& Unwin Brothers, 1951.

1955.

. Caminhos para a liberdade. São Paulo: Companhia Editora Nacional,

. Educação e ordem social. São Paulo: Companhia Editora Nacional, 1956a.

. Educação e vida perfeita. São Paulo: Companhia Editora Nacional, 1956.

. Ensaios Impopulares. São Paulo: Companhia Editora Nacional, 1956c.

. Ensaios céticos. São Paulo: Companhia Editora Nacional, 1957a.

. O poder, uma nova análise social. São Paulo: Companhia Editora Nacional, 1957b.

. Princípios de reconstrução social. São Paulo: Companhia Editora Nacional, 1958a.

. Retratos de Memória. São Paulo: Companhia Editora Nacional, 1958b.

1962. . Tem futuro o homem? Rio de Janeiro: Editora Civilização Brasileira,

. Crimes de Guerra no Vietnã. Rio de Janeiro: Editora Paz e Terra, 1967.

. A minha concepção do mundo. Brasília: Brasília Editora, 1970.

. Ética e Política na sociedade humana. Rio de Janeiro: Zahar, 1977.

. Ideais Políticos. Rio de Janeiro: Bertrand Brasil, 2001.

. História do Pensamento Ocidental. Rio de Janeiro: Ediouro, 2003.

. No que acredito. Porto Alegre: L\&PM, 2009.

SILVA, A. R. da; VALLE, J. C. A. do. O mérito e o mito da democracia racial: tópicos de uma discussão. Revista Internacional de Educación para la Justicia Social (RIEJS), 3 (2), 235-250, dezembro, 2014.

VALLE, J. C. A. do. História oral: uma possibilidade de justiça cognitiva no currículo. Revista Ars Histórica Rio de Janeiro, UFRJ, 7, 124-138, junho, 2014.

. Insubordina-te, educação matemática! Responsabilidade e paz em

Bertrand Russell. 2015. 266f. Dissertação (Mestrado em Educação). Faculdade de Educação, Universidade de São Paulo. São Paulo, 2015.

Recebido em 12 de Abril de 2015. Aprovado em 31 de Julho de 2016. 